\title{
What Would It Be Like to Lose One's Nose? Gogol's The Nose and the Astronomer Tycho Brahe
}

\section{Kun Hwang}

Ethics Editor, Archives of Plastic Surgery

Department of Plastic Surgery, Inha University School of Medicine, Incheon, Korea

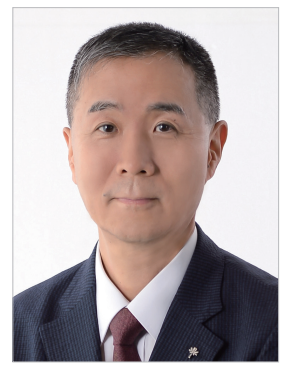

"The nose looked at the Major and frowned a little." Nikolai Gogol, The Nose

Last year at the Metropolitan Opera House, I enjoyed the opera The Nose, directed by William Kentridge. In the opera, a man named Major Kovalyov woke up one morning and found that his nose had gone missing in the night. The nose had developed a life of its own (Fig. 1). Although a police officer returned the nose to Kovalyov, a doctor was unable to reattach the nose. On 13 th day after losing his nose, he woke up to find his nose reattached.

This satirical opera by Shostakovich was adapted from the classic short story by Nikolai Gogol (1809-1852). Kovalyov's nose acted as the source of his own pride; thereafter, the loss of his nose represented a loss of his identity. Since his identity was primarily defined by his outward appearance, the loss of that appearance devastated him.

Gogol wrote this story since he had an oddly shaped nose, which was often the subject of self-deprecating jokes in his letters [1]. Gogol opted for a comedy marked by the fantastic. However, parody is just a method of obscuring human suffering [2].

Today, an amputated nose can be reattached with microvascular anastomosis. If the stump is lost, the nose can be reconstructed with forehead flaps. In the Renaissance period, however, a nasal prosthesis was used instead.

Tycho Brahe (1546-1601) was a Danish astronomer. After his death, his assistant, Johannes Kepler (1571-1630), used Brahe's astronomical data and proposed the 3 laws of planetary motion: (1) the orbit of a planet is an ellipse with the sun at one of the two foci; (2) a line segment joining a planet and the sun sweeps out equal areas during equal intervals of time; and (3) the square of the orbital period of a planet is proportional to the cube of the semi-major axis of its orbit.

When he was 20, Brahe lost part of his nose in a sword duel with his third cousin, Manderup Parsberg. Manderup's blade cut away most of the nasal bridge, leaving the nasal cavity and septum exposed.

To hide his deformity, he constructed a prosthetic device made of wax, but it was unsatisfactory. Thus, he made a mold around the wax nose and fabricated a brass prosthesis. An artist matched the color of his skin. The prosthesis was held in place with glue. It is thought that this deformity altered his personality. He became defensive, depressive, and secretive [3].

Today, nasal prostheses made of polydimethylsiloxane are flexible and designed to move with the skin. They are retained by using an adhesive or osseointegrated implants.

A recent study found that the quality of life of patients with a facial prosthesis was reduced in comparison with a healthy group when the acquired defects were located at the eye or nose. The patients' body image and sense of their own sexual attractiveness were diminished. Some patients even believed they gave off an unpleasant odor [4].

Plastic surgeons should reflect on the examples of Major Kovalyov and Tycho Brahe as they consider the role of psychological care for patients who have lost a body part.

\section{ORCID}

Kun Hwang https://orcid.org/0000-0002-1994-2538 


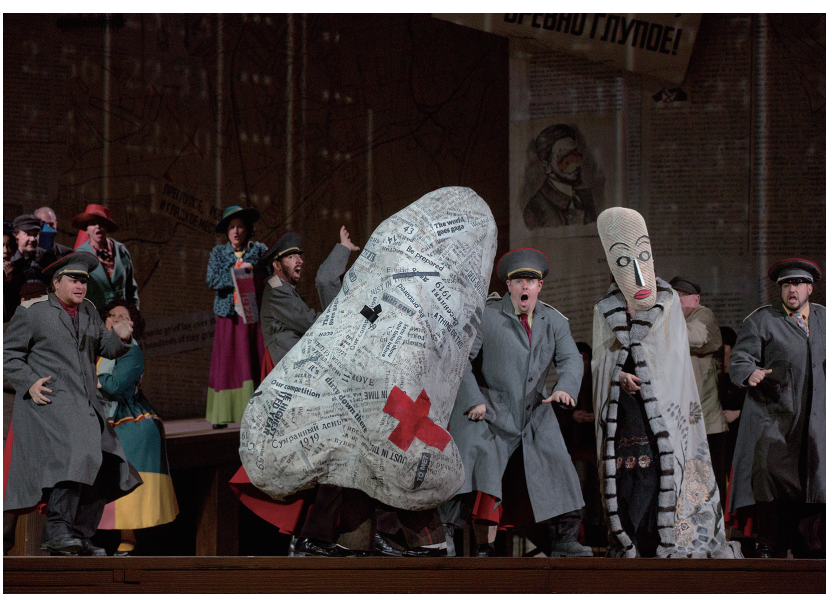

Fig. 1.

The poster of the opera The Nose, as performed at the Metropolitan Opera House in New York City (reproduced with permission from "Courtesy of Metropolitan Opera").

\section{REFERENCES}

1. Sicher E. Dialogization and laughter in the dark, or how Gogol's nose was made: parody and literary evolution in Bachtin's theory of the novel. Russ Lit 1990;28:211-33.

2. Tainmont J. The ear and the nose in literary parodies. the "hymn of deafness" by Du Bellay and "the nose" by Gogol. B-ENT 2011;7:309-17.

3. Greisman HC. Tycho Brahe: astronomer of Renaissance Denmark. Clin Plast Surg 1983;10:629-33.

4. Klein M, Menneking H, Spring A, et al. Analysis of quality of life in patients with a facial prosthesis. Mund Kiefer Gesichtschir 2005;9:205-13.

Correspondence: Kun Hwang

Department of Plastic Surgery, Inha University School of Medicine, 27 Inhang-ro, Jung-gu, Incheon 22332, Korea

Tel: +82-32-890-3514, Fax: +82-32-890-2918, E-mail: jokerhg@inha.ac.kr

No potential conflict of interest relevant to this article was reported.

Received: 29 Jun 2017 • Revised: 2 Jul 2017 • Accepted: 3 Jul 2017

pISSN: 2234-6163 • elSSN: 2234-6171

https://doi.org/10.5999/aps.2017.44.4.257 • Arch Plast Surg 2017;44:257-258 